\title{
Reduction in Eddy Current Loss on Rotor of SPMSM Driven by Inverter
}

$\begin{array}{llll}\text { Masashi Sawada* }^{*} & \text { Member, } & \text { Koji Hashimoto } & \text { Member } \\ \text { Yuji Kinoshita** }^{* *} & \text { Non-member, } & \text { Masanori Kuroda** } & \text { Non-member } \\ \text { Tomoaki Tamiya }^{* *} & \text { Member, } & \text { Yuji Shindo } & \text { Member } \\ & \text { Yoshihiro Kawase } & \text { Member } & \end{array}$

(Manuscript received Feb. 5, 2014, revised July 15, 2014)

\begin{abstract}
This paper proposes a rotor damper as a device to reduce the rotor loss. The rotor damper is a thin copper plate inserted between the magnets and the rotor shaft. The eddy current in this damper can suppress the flux harmonics with minimum rotor loss. Both analytical estimation and numerical simulation are performed. The experimental results show that the technique is effective and practical.
\end{abstract}

Keywords: SPMSM, rotor damper, eddy current, skin effect, PWM

\section{Introduction}

Depending on the mechanical structure of the rotors, permanent magnet motors can be classified into two types, surface permanent magnet synchronous motors (SPMSM) and interior permanent magnet synchronous motors (IPMSM). Their schematic structures are shown in Fig. 1. One of the major factors to restrict the critical or the maximum speed of the rotor is the frequency of bending resonance. In the high speed use, SPMSMs with a solid rotor core are often preferred because their large stiffness of the rotors makes the resonance frequency higher ${ }^{(1)}$.

It is known that the excessive temperature rise causes the demagnetization of the permanent magnets. When we adopt the rotor of SPMSM as mentioned above, the temperature rise due to the eddy current loss become major concern in designing the rotor. There are two reasons why the rotor temperature tends to rise.

The first reason comes from the solid rotor itself ${ }^{(2)}$. In the solid rotor of SPMSM, the eddy current due to the spatial and time harmonics of the magnetic flux is much larger than that of laminated magnetic sheets. This is significant when the motor is driven by PWM inverters. Thus the sinusoidal filters at the output of PWM inverters are sometimes required.

The second reason is the existence of the rotor sleeve which fastens the magnet pieces against the large centrifugal force. The shrink ring, for example the FRP, is often used as a sleeve. But the thermal conductivity of such material is usually much lower than that of metals. Therefore, even the small eddy current loss causes the large temperature rise. Needless to say, the adoption of the metal sleeve gives

\footnotetext{
${ }^{*}$ Kawasaki Technology Co., Ltd.

1-1, Kawasaki-cho, Akashi, Hyogo 673-8666, Japan

${ }^{* *}$ Kawasaki Heavy Industries, Ltd.

1-1, Kawasaki-cho, Akashi, Hyogo 673-8666, Japan

${ }^{* * *}$ Department of Electrical, Electronic and Computer Engineering, Graduate School of Engineering, Gifu University

1-1, Yanagito, Gifu 501-1193, Japan
}

opposite effect, since the eddy current in the sleeve yields incredibly large loss ${ }^{(3)(4)}$.

In the case of the IPMSM, it is reported that the magnet split is effective for the reduction of the eddy current in the magnet ${ }^{(5)-(7)}$. Although the same thing can be said about the SPMSM, another problem arises by splitting the magnet. If the eddy current in the magnet is reduced, then the fluctuation of the flux is applied to the rotor shaft directly. This yields the increase of the loss on the rotor shaft, that is, only the part of heating is shifted ${ }^{(14)}$. Needless to say, the split of rotor shaft is practically impossible, since it causes the severe deterioration of the rotor strength.

Compared with the IPMSM, the SPMSM has one more weak point about the rotor loss. That is the narrow gap between the surface of the magnet and the teeth of the stator. In the case of the IPMSM, the magnet pieces are covered by the laminated magnetic sheets of the rotor core. Thus the spatial harmonics of flux in the air gap is averaged and smoothed.

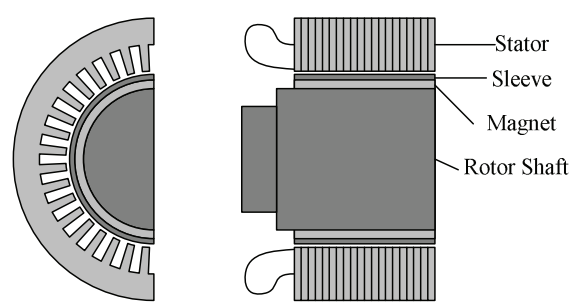

(a) SPMSM


(b) IPMSM

Fig. 1. Structure of SPMSM and IPMSM. 


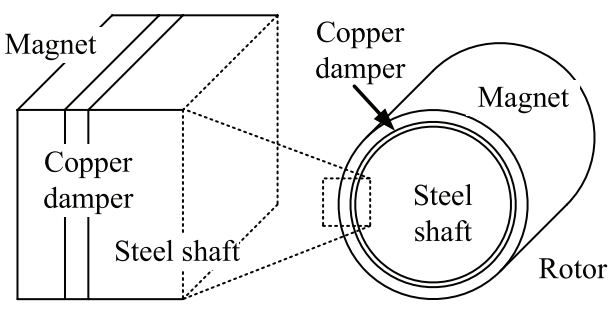

Fig. 2. The rotor damper.

This yields the reduction of flux fluctuation and enables the multipolar motors with concentrated windings ${ }^{(8)-(10)}$. Conversely, the SPMSM is susceptible to the spatial harmonics of the flux. In order to reduce the spatial harmonics, the distributed windings are often preferred rather than the concentrated windings. The arrangement of slots and coils of the stator should be carefully determined ${ }^{(11)(12)}$. Furthermore, the slot-less stator is sometimes employed in severe conditions ${ }^{(13)}$.

For the circumstance mentioned above, the techniques for reducing eddy current loss in the rotor of SPMSM may considerably different from those for the IPMSM. This paper propose a rotor damper as a device for the rotor loss reduction ${ }^{(14)(15)}$. The rotor damper is a thin copper plate inserted between magnets and a shaft as illustrated in Fig. 2. The eddy current in this damper can push back the flux harmonics with minimum rotor loss. In this paper, analytical estimation and numerical simulation of the rotor damper are reported. Experimental results show that the technique is effective and practical.

\section{Rotor Damper}

2.1 Principle of Rotor Damper In the SPMSM, the three phase armature current of the fundamental frequency generates rotating magnetic flux which synchronize to the rotor rotation. This flux can reach to inner of the rotor shaft, since the flux is stationary on the rotating coordinate. Conversely, high frequency PWM harmonics and spatial flux harmonic can flow only near the surface of the rotor, because of the skin effect on the rotor shaft. The paths of this flux are schematically indicated in Fig. 3.

By using the $\mathrm{d}-\mathrm{q}$ axis equivalent circuit of the rotating machine, the behavior of the eddy current on the rotor can be discussed easily. The $d-q$ axis equivalent circuits are illustrated in Fig. $4^{(16)(17)}$. In this figure, the exciting winding of usual synchronous machine is replaced with the equivalent circuit for magnet pieces which is denoted by $L_{M}, R_{M}$ and $I_{m}$. Furthermore, it is supposed that the eddy current flows in equivalent circuits with inductance $L_{d}, L_{q}$ and the resistance $R_{d}$ and $R_{q}$.

Let $V_{d}$ and $V_{q}$ be the motor terminal voltage in d-q axis. The voltage $V_{d}$ and $V_{q}$ are assumed as a DC voltage, since they present the fundamental sinusoidal voltages in original AC circuit. All the current caused by $V_{d}$ and $V_{q}$ flows to mutual inductance $L_{a d}$ or $L_{a q}$, since their DC impedances are zero. The fundamental flux does not induce the eddy current on the rotor at all.

The PWM voltages on $\mathrm{d}-\mathrm{q}$ axis, $v_{d_{-} P W M}$ and $v_{q_{-} P W M}$, are defined to denote the PWM harmonics. Since the mutual inductance $L_{a d}$ or $L_{a q}$ make large impedance at the PWM

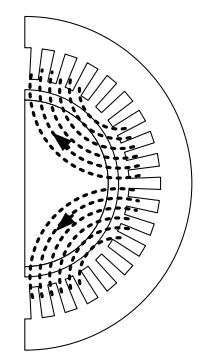

(a) Fundamental flux.

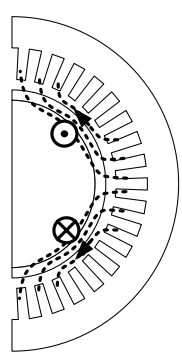

(b) PWM harmonics.
Fig. 3. Distribution of flux on the rotor.
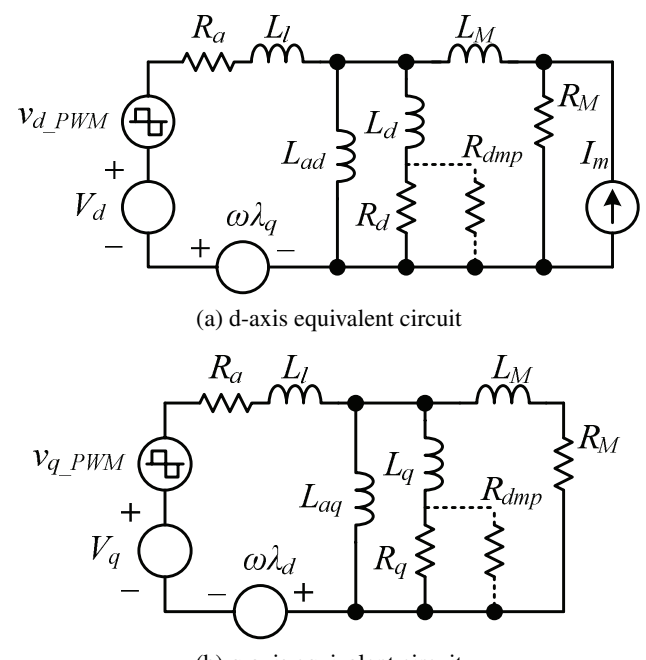

(b) q-axis equivalent circuit

Fig. 4. Equivalent circuits with rotor damper.

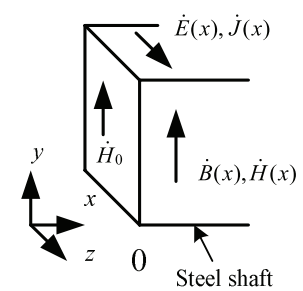

(a) Without damper

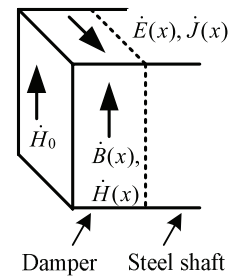

(b) With damper.
Fig. 5. Magnetic field parallel to rotor surface.

frequency, the harmonic current flows to the rotor or the magnets.

The harmonic current in $R_{d}, R_{q}$ and $R_{M}$ cause the eddy current loss in the rotor and magnet pieces. If the resistances $R_{d}$, $R_{q}$ are short-circuited by low resistance $R_{d m p}$, these losses can be reduced. Note that the increase of armature current caused by paralleling the resistance $R_{d m p}$ is restricted by armature impedance $R_{a}$ and $L_{l}$. Furthermore, paralleling the resistance $R_{d m p}$ may yield the reduction of eddy current loss in the magnet pieces, because the harmonic voltage applied to the serially connected inductor $L_{M}$ and resistor $R_{M}$ is reduced. That is the basic idea of the rotor damper. More detailed discussions are done in following sections by using the theory of skin effects.

2.2 Skin Effect and Surface Resistivity Especially in the high frequency range of the PWM harmonics, the skin effect plays important rolls for the eddy current loss on the rotor. Hence, the theory of skin effect is summarized.

Let us consider the flux distribution in the magnetic material in the form of infinite plate, as shown in Fig. 5(a). The 
Table 1. Material constants.

\begin{tabular}{c|c|c|c}
\hline Part & Magnet & Rotor shaft & Damper \\
\hline Material & NEOMAX $®$ & SCM430 & Copper \\
\hline Relative permeability [-] & 1.05 & 440 & 1.0 \\
\hline Conductivity $[\mathrm{S} / \mathrm{m}]$ & $0.77 \mathrm{E} 6$ & $4.5 \mathrm{E} 6$ & $59 . \mathrm{E} 6$ \\
\hline Skin depth $[\mathrm{mm}]$ & 6.3 & 0.13 & 0.73 \\
\hline Surface resistivity $\left[\Omega \mathrm{m}^{2}\right]$ & $0.21 \mathrm{E}-3$ & $1.8 \mathrm{E}-3$ & $0.023 \mathrm{E}-3$ \\
\hline
\end{tabular}

The values of skin depth and surface resistivity are taken at $8 \mathrm{kHz}$.

differential equation is given by (1), where the variable $\omega$ denotes the angular velocity, the constants $\sigma$ and $\mu$ denote the electric conductivity and the magnetic permeability respectively. From (1), the Helmholtz equation (2) can be derived. Solving (2) with boundary condition $\dot{H}(0)=\dot{H}_{0}$ yields the magnetic distribution (3). Here, the $\delta$ is the skin depth defined as (4).

$$
\begin{aligned}
& \frac{\partial \dot{E}(x)}{\partial x}=j \omega \mu \dot{H}(x), \quad \frac{\partial \dot{H}(x)}{\partial x}=\dot{J}(x)=\sigma \dot{E}(x) \cdots \\
& \frac{\partial^{2} \dot{H}(x)}{\partial x^{2}}-j \omega \sigma \mu \dot{H}(x)=0 \ldots \ldots \ldots \ldots \ldots \ldots
\end{aligned}
$$

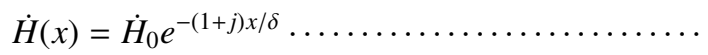

$$
\begin{aligned}
& \delta=\sqrt{2 / \omega \sigma \mu} \text {. }
\end{aligned}
$$

From (1) and (3), the eddy current $\dot{J}(x)$ inside the material is given by the followings.

$$
\dot{J}(x)=\frac{\partial \dot{H}}{\partial x}=-\frac{1+j}{\delta} \dot{H}_{0} e^{-(1+j) x / \delta} \ldots \ldots \ldots \ldots \ldots
$$

The distribution of eddy current loss is expressed as (6), and the loss per unit area is given by (7). Where, the $R$ defined by (8) is regarded as an equivalent surface resistivity when the magnetic field $\dot{H}_{0}$ is applied parallel to the surface of the material. The eddy current loss is proportional to this surface resistivity for supplied magnetic field. This surface resistivity is widely used in the area of RF engineering ${ }^{(18)(19)}$. One should take care not to confuse it with the surface resistivity used in the area of material test.

$$
\begin{aligned}
& W(x)=\frac{|\dot{J}(x)|^{2}}{2 \sigma}=\frac{\omega \mu H_{0}^{2}}{2} e^{-2 x / \delta} \ldots \ldots \ldots \ldots \ldots \ldots \\
& W=\int_{0}^{\infty} W(x) d x=\frac{1}{2}\left(\frac{\omega \mu \delta}{2}\right) H_{0}^{2}=\frac{1}{2} R H_{0}^{2} \ldots \ldots \ldots \\
& R=\sqrt{\frac{\omega \mu}{2 \sigma}}=\frac{1}{\delta \sigma} \ldots \ldots \ldots \ldots \ldots \ldots \ldots \ldots
\end{aligned}
$$

The surface resistivity defined in (8) can also be interpreted as a circuit resistance on the surface of the rotor, since it is the inverse of the product of conductivity $\sigma$ and skin depth $\delta$. Therefore, this surface resistivity can be regarded as the resistance $R_{d}$ and $R_{q}$ in the equivalent circuits given by Fig. 4 .

The material constants of permanent magnet, the rotor shaft and damper are shown in Table 1. It is notable that the surface resistivity of the copper is about one eightieth of that of steel. The rotor damper uses this property.

2.3 Loss Reduction The magnetic field on the rotor surface may have parallel and orthogonal components to the rotor surface. But it is difficult to describe this magnetic field intelligibly, because the rotor has a cylindrical shape. In order to help ones understanding, the round rotor is schematically

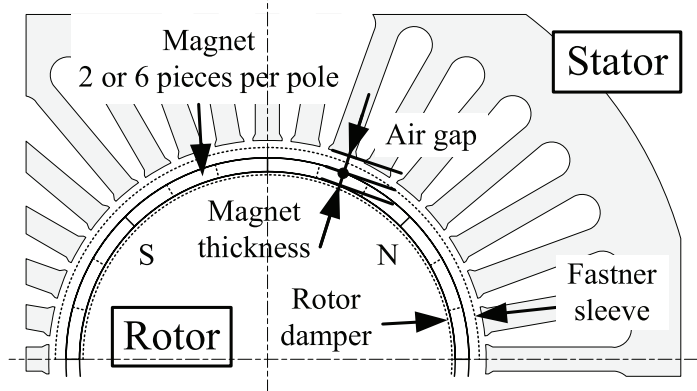

(a) Structure of the motor.

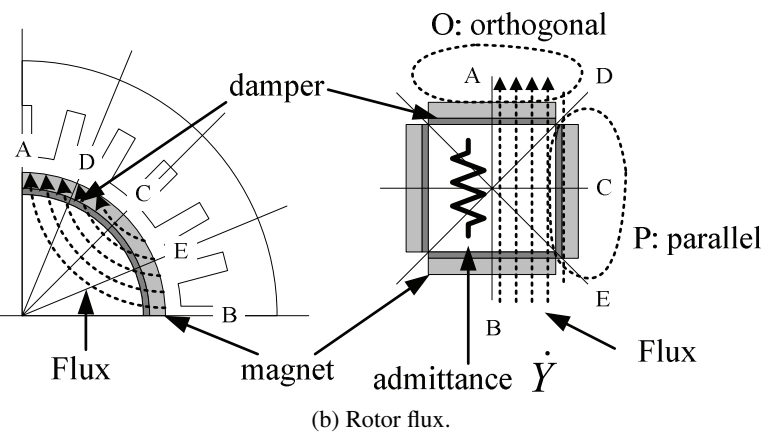

Fig. 6. Rotor model.

transformed to rectangle form as shown in Fig. 6. This helps to apply the theory of eddy current in infinite plane summarized in previous section. The magnetic field at the area $\mathrm{P}$ in Fig. 6(b) is assumed that the flux is parallel to the rotor surface, while the area $\mathrm{O}$ is that the flux is orthogonal to the rotor surface.

Here, the parallel component of the magnetic field is studied first. From (7), the eddy current loss is proportional to the square of the magnetic field, which is parallel to the surface of the materials. When the shaft is covered by thin copper plate, the parallel magnetic field inside the copper plate is reduced. And the diminution of the magnetic field is determined by the skin depth of the copper. Because the surface resistivity of the copper is much smaller than that of steel, the eddy current loss of this copper plate is quite little compared to that of the steel rotor shaft. After all, the total eddy current loss of the rotor shaft can be reduced.

Figure 7 shows the distribution of the magnetic field, the current density, the flux density and the loss, when the rotor damper is installed. Here, the thickness of the rotor damper is varied from $0.0 \mathrm{~mm}$ to $0.8 \mathrm{~mm}$. Note that the reduction rate of the loss shown in Fig. 7(d) is larger than the reduction rate of the eddy current shown in Fig. 7(b). This is because the loss is proportional to the square of the eddy current.

When the rotor damper is installed as Fig. 5(b), the eddy current loss (7) is modified as follows.

$$
W=\frac{1}{2} R_{d} H_{0}^{2}\left(1-e^{-2 D / \delta}\right)+\frac{1}{2} R_{S} H_{0}^{2} e^{-2 D / \delta} \ldots
$$

Here, $R_{d}$ and $R_{s}$ are surface resistivity of the damper and the steel shaft respectively. The constant $D$ is the thickness of the rotor damper. The loss on the rotor with the rotor damper is shown in Fig. 8. At the frequency of $8 \mathrm{kHz}, \mathrm{PWM}$ carrier frequency of our study, the loss is reduced more than by half when the thickness of damper is set to $0.4 \mathrm{~mm}$.

Although the existence of the magnet pieces is ignored in 

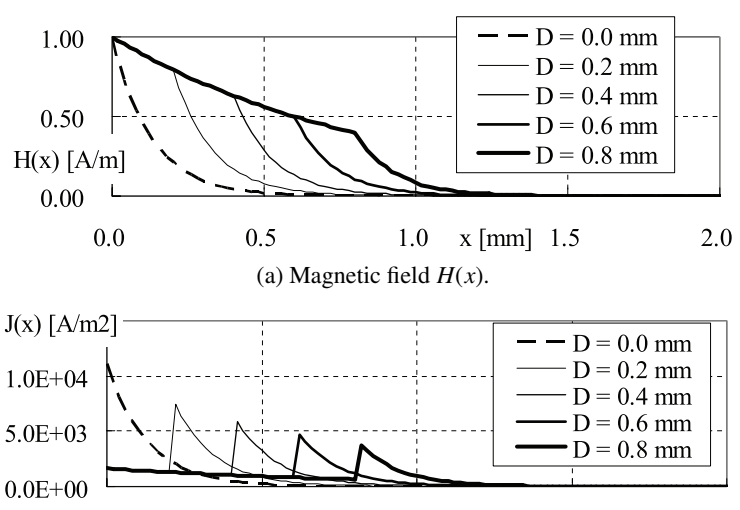

$\begin{array}{lllll}0.0 & 0.5 & 1.0 & \mathrm{x}[\mathrm{mm}] & 1.5\end{array}$

(b) Current density $J(x)$

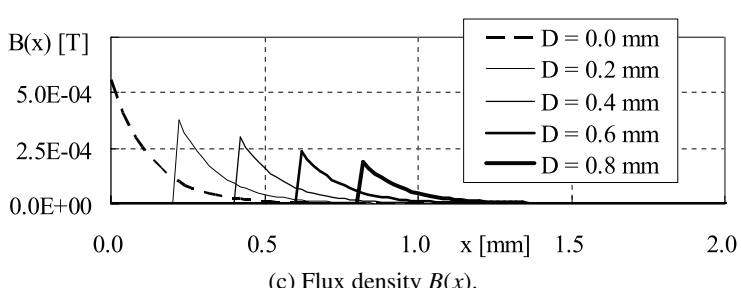

(c) Flux density $B(x)$.

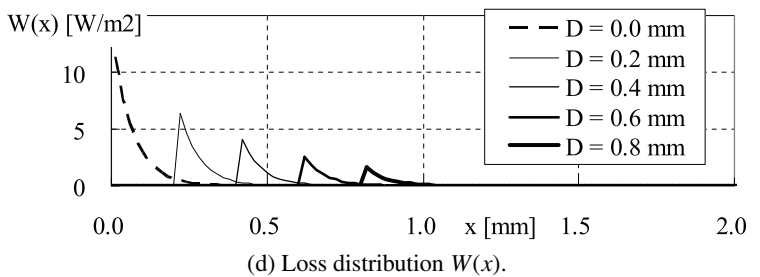

Fig. 7. Effect of the rotor damper.



Fig. 8. Reduction of eddy current loss on the shaft.

the above discussion, it is clear that the existence of the magnet does not affect the loss reduction of the rotor shaft. So far as the theory of eddy current in infinite plane is applied, the rotor damper can only reduce the eddy current loss inside the damper.

In the next section, the FEM analysis shows that the loss in magnet is also reduced by rotor damper. In order to clarify this effect, here we calculate the orthogonal component of the magnetic field against the rotor surface shown in Fig. 6. This magnetic field corresponds to the flux passing through the rotor.

If the external magnetic field is applied as Fig. 6, the total flux in the rotor is given by the following. Here, $\delta_{c}$ and $\delta_{s}$ are skin depth of the damper and the rotor shaft.

$$
\dot{\Phi}=\frac{\dot{H}_{0}}{1+j}\left[\mu_{0} \delta_{c}+\left(\mu_{s} \delta_{s}-\mu_{0} \delta_{c}\right) e^{-(1+j) D / \delta_{c}}\right] \ldots
$$

By using (10), the admittance of the magnetic circuit, which is indicated in Fig. 6, is defined by (11).

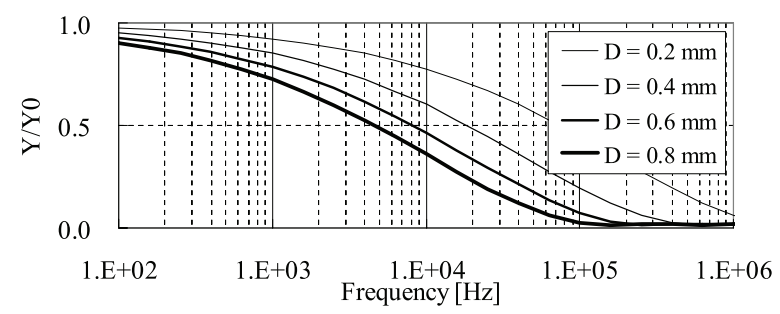

Fig. 9. Decrease of admittance of the magnetic circuit.

$$
\dot{Y}=\dot{\Phi} / \dot{H}_{0}=\frac{1}{1+j}\left[\mu_{0} \delta_{c}+\left(\mu_{s} \delta_{s}-\mu_{0} \delta_{c}\right) e^{-(1+j) D / \delta_{c}}\right]
$$

Let $\dot{Y}_{0}$ be a magnetic admittance when the thickness of the damper is zero. The ratios of the admittance $\dot{Y} / \dot{Y}_{0}$ are illustrated in Fig. 9 for various thickness of the damper. In the high frequency, the magnetic admittance is reduced relatively to that of shaft without damper. This provides the reduction of PWM harmonics of orthogonal flux through magnet pieces in Fig. 6(b). After all, the rotor damper can reduce the eddy current loss in the magnet.

It should be noted that the effect of the damper in the area $\mathrm{O}$ of Fig. 6 is not evaluated in the above discussion. Thus the actual eddy current loss of the magnet is expected to be smaller than the evaluation. In addition to the PWM harmonics, there is the loss by the slot effect of the stator windings. However, it is very difficult to evaluate them analytically, because it requires the complex field analysis. So, the finite elements analysis should be used for more precise evaluations.

\section{Finite Elements Analysis}

3.1 Motor and Driving Condition The eddy current loss on the rotor is estimated by finite elements analysis in this section. The 4-pole high-speed synchronous motor is driven by a PWM inverter. Constants of the motor and the driving inverter are shown in Table 2. Dimensions for the magnetic circuit, including the gap length and thickness of magnet, are also listed in Table 2. The magnet shape is arch i.e. segment type with constant thickness. In all the simulations and experiments, the number of magnet split in axial direction is not changed. Only the number of magnet split in hoop or circumferential direction are changed. The split number is the number of magnet segments per pole. Six segments of magnet means 24 magnet pieces on whole circumference, since the number of poles of this motor is four.

The waveforms of the armature current are chosen sinusoidal and PWM. In order to obtain the current waveform driven by the PWM inverter, Spice circuit simulator is used. In addition to the usual waveform of 2-level PWM inverter, that of 3-level inverter is obtained. The filter reactors are inserted between the 2-level PWM inverter and the motor, while the 3-level inverter is connected to the motor directly. The circuit schematics of the inverter and motor are illustrated in Fig. 10. The waveform of 2 and 3-level inverters are illustrated in Fig. 11. The FFT analysis of armature current is shown in Fig. 12. Current harmonics are observed in the frequency range of $3 \mathrm{kHz}$ to $10 \mathrm{kHz}$ or more.

3.2 Simulation Results The MagNet 2D/3D Electromagnetic field simulator of Inforitica Corp. is used. The 
Table 2. Constants of the motor and inverter.

\begin{tabular}{c|c}
\hline Rated Power $[\mathrm{kW}]$ & 230 \\
\hline Rated speed [1/min] & 27,000 \\
\hline Rated armature current [Arms] & 425 \\
\hline Number of poles [-] & 4 \\
\hline Number of slots [-] & 36 \\
\hline Armature inductance $[\mu \mathrm{H}]$ & 70 \\
\hline Windings & 4.0 \\
\hline Thickness of permanent magnet $[\mathrm{mm}]$ & 2 or 6 per pole \\
\hline Division of magnet in circumferential & 5.0 \\
\hline Length of the air gap [mm] & 8.0 \\
\hline including the fastener sleeve & 55 \\
\hline \hline PWM carrier frequency $[\mathrm{kHz}]$ & 2 or 3 \\
\hline Filter inductance $[\mu \mathrm{H}]$ &
\end{tabular}

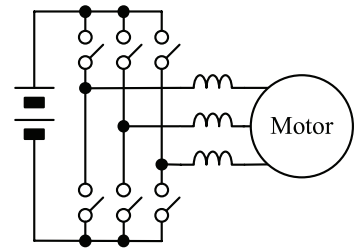

(a) 2-level with reactors

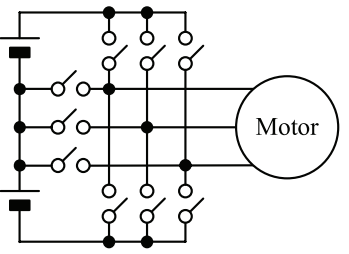

(b) 3-level
Fig. 10. Driving inverters.

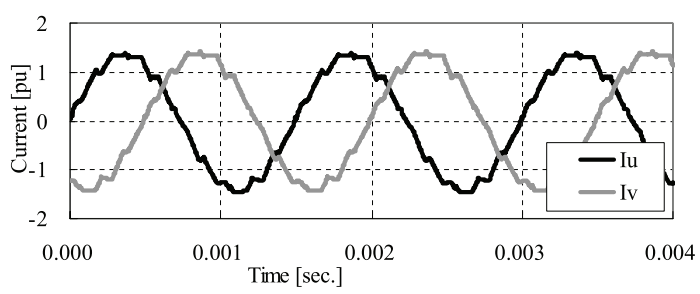

(a) 2-level with reactors

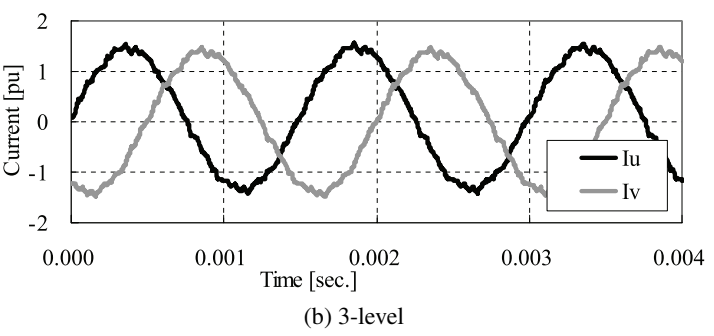

Fig. 11. Armature current.

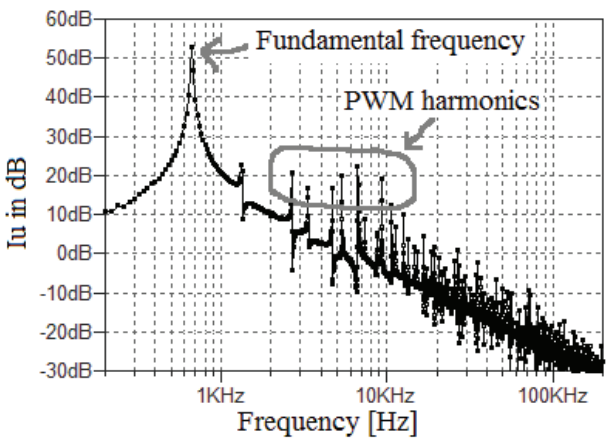

Fig. 12. FFT analysis of armature current in 2-level inverter.

simulation is formulated as a two-dimensional problem. As shown in Table 1, skin depth of the rotor shaft at PWM frequency is only $0.13 \mathrm{~mm}$. In order to reduce the discretization

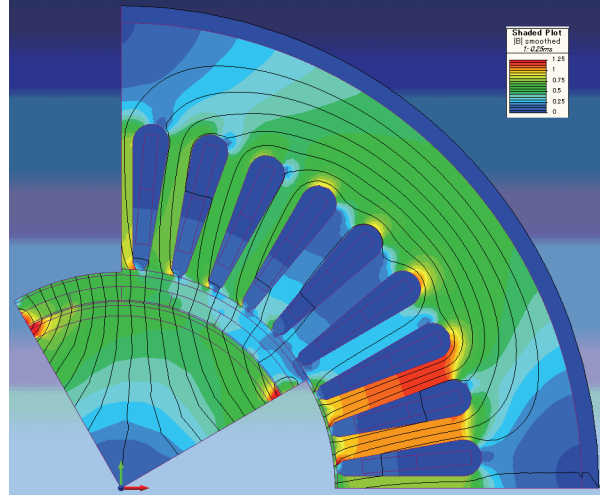

Fig. 13. Flux density of the motor.

Table 3. Simulation results.

\begin{tabular}{|c|c|c|c|c|c|c|c|}
\hline \multirow{2}{*}{ No. } & \multirow{2}{*}{$\begin{array}{c}\text { current } \\
\text { waveform }\end{array}$} & \multirow{2}{*}{$\begin{array}{l}\text { magnet } \\
\text { split }\end{array}$} & \multirow{2}{*}{$\begin{array}{c}\text { thickness } \\
\text { of damper } \\
{[\mathrm{mm}]}\end{array}$} & \multicolumn{4}{|c|}{ eddy current loss [W] } \\
\hline & & & & rotor & damper & magnet & $\Sigma$ \\
\hline 1 & \multirow{8}{*}{ Sinusoidal } & \multirow{4}{*}{2} & 0.0 & 2.5 & 0.0 & 22.7 & 25.2 \\
\hline 2 & & & 0.2 & 0.5 & 10.7 & 12.6 & 23.8 \\
\hline 3 & & & 0.4 & 0.2 & 7.8 & 10.1 & 18.1 \\
\hline 4 & & & 0.6 & 0.1 & 5.9 & 9.5 & 15.4 \\
\hline 5 & & \multirow{4}{*}{6} & 0.0 & 4.9 & 0.0 & 15.5 & 20.4 \\
\hline 6 & & & 0.2 & 0.6 & 12.2 & 9.6 & 22.4 \\
\hline 7 & & & 0.4 & 0.2 & 8.6 & 8.2 & 17.0 \\
\hline 8 & & & 0.6 & 0.1 & 6.3 & 7.7 & 14.1 \\
\hline 9 & \multirow{8}{*}{$\begin{array}{l}\text { 2-level } \\
\text { with } \\
\text { reactor }\end{array}$} & \multirow{4}{*}{2} & 0.0 & 43.8 & 0.0 & 72.4 & 116.2 \\
\hline 10 & & & 0.2 & 1.1 & 22.4 & 16.6 & 40.1 \\
\hline 11 & & & 0.4 & 0.4 & 14.4 & 14.1 & 28.9 \\
\hline 12 & & & 0.6 & 0.2 & 10.5 & 13.6 & 24.3 \\
\hline 13 & & \multirow{4}{*}{6} & 0.0 & 96.1 & 0.0 & 41.0 & 137.2 \\
\hline 14 & & & 0.2 & 1.2 & 25.1 & 12.6 & 39.0 \\
\hline 15 & & & 0.4 & 0.4 & 15.6 & 11.3 & 27.3 \\
\hline 16 & & & 0.6 & 0.2 & 11.2 & 10.9 & 22.3 \\
\hline 17 & \multirow{4}{*}{ 3-level } & \multirow{4}{*}{6} & 0.0 & 68.3 & 0.0 & 36.7 & 105.0 \\
\hline 18 & & & 0.2 & 1.6 & 25.1 & 14.4 & 41.1 \\
\hline 19 & & & 0.4 & 0.6 & 16.5 & 13.0 & 30.1 \\
\hline 20 & & & 0.6 & 0.3 & 12.2 & 12.6 & 25.1 \\
\hline 21 & $\begin{array}{l}\text { 2-level } \\
\text { with } \\
\text { reactor }\end{array}$ & 2 & $\begin{array}{c}0.4 \text {, outer } \\
\text { side of the } \\
\text { magnet }\end{array}$ & 0.5 & 99.5 & 5.3 & 105.3 \\
\hline
\end{tabular}

error due to this small skin depth, the maximum element size at the surface of the rotor shaft is chosen to $0.05 \mathrm{~mm}$. By using the periodic boundary condition, one fourth of the motor is modeled. An example of simulated flux density is as shown in Fig. 13.

In the simulation, the thickness of the copper-plating rotor damper is chosen to $0.0,0.2,0.4,0.6 \mathrm{~mm}$. The permanent magnet is split to two and six pieces per pole. The simulated results are summarized in Table 3 and Fig. 14.

In the first eight cases, simulations are done with sinusoidal drives. In these cases, the eddy currents are caused by partial harmonics of the flux density due to the winding arrangement and the slot effect of the stator core. So the eddy current losses are not so large. Maximum value of the loss is $25.2 \mathrm{~W}$ in the case of no damper and the magnet split is two. The difference about the number of magnet splits is little. The effectiveness of the rotor damper is also little.

Next eight cases, from No. 9 to 16, are simulated with twolevel inverter drives. Without the damper, No. 9 and 13, the 


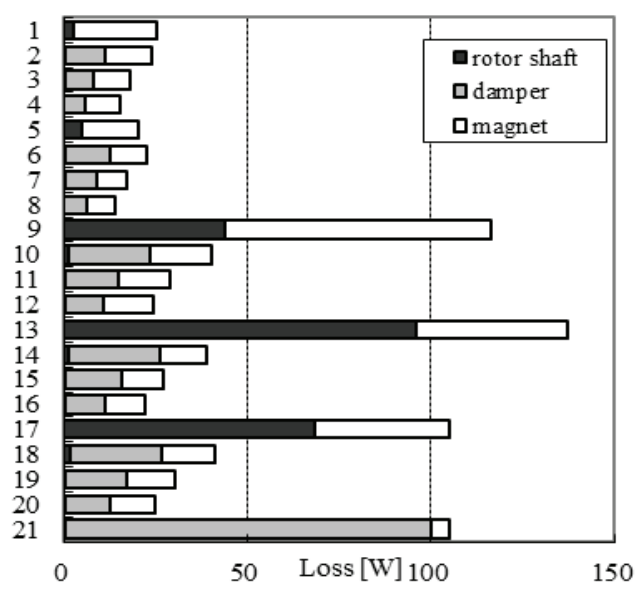

Fig. 14. Eddy current loss.

eddy current losses are increased more than four times of sinusoidal drives. It is impressive that the magnet split causes opposite effect. The total loss with 6-pieces magnet is larger than that of 2-pieces. In case of the 6-pieces split, the eddy current loss in the magnet is reduced by half, while the loss in the rotor shaft is doubled. Because the eddy current in the magnet is reduced, the fluctuation of the flux is applied to the rotor shaft directly ${ }^{(14)}$.

By applying the rotor damper, the total eddy current loss is reduced as expected. Even the damper with $0.2 \mathrm{~mm}$ thickness, the loss of the rotor shaft is drastically reduced. Moreover, the loss in the magnet is reduced less than one third. Instead, the eddy current loss in the damper is increased.

The simulation results when the motor is driven by 3-level inverter are also listed in Table 3. Eddy current loss in case of 3 -level inverter is almost same to that of 2-level inverters. By combining the rotor damper with 3-level inverter, expensive and bulky reactors can be eliminated.

Instantaneous distributions of eddy current are shown in Fig. 15. In these simulations the motor is driven by 2-level inverter with reactors. At the surface of the rotor shaft in Fig. 15(a) or at the rotor damper in Fig. 15(b), eddy currents are concentrated. In the pieces of permanent magnet, periodic distribution of eddy current loss is observed as if it is caused by the slot effect. This does not imply that that the loss is caused only by the slot harmonics. Assume that the rotor completely remains stationary and is not rotating. When PWM current is applied to the armature winding, the deviation of flux density near the tooth top is larger than that on stator slot. So the induced voltage is distributed periodically on the rotor. This provides the periodic distribution of eddy current loss on the rotor. The time domain PWM harmonics causes the eddy current loss with striped pattern due to the slots allocation.

3.3 Installation Place of the Damper Instead of surface of the rotor shaft, the rotor damper can be placed on outside the magnet pieces. According to the discussion based on the equivalent circuit Fig. 4, there may be no difference between the damper installed behind the magnet and that outside the magnet.

In order to clarify this question, simulation for damper placed outside the magnet is done. The magnet split is two and the thickness of the damper is $0.4 \mathrm{~mm}$. The current

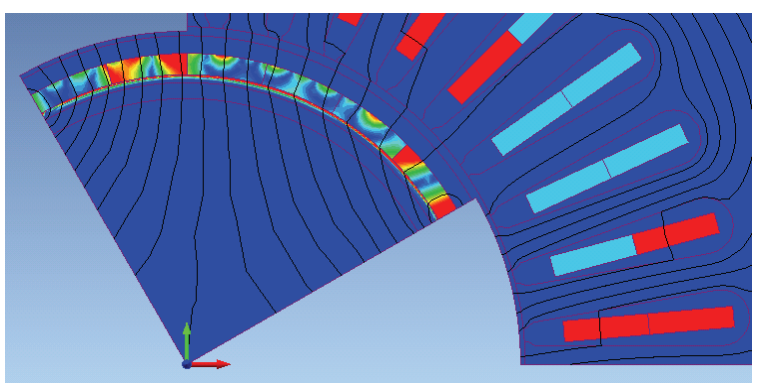

(a) No damper.

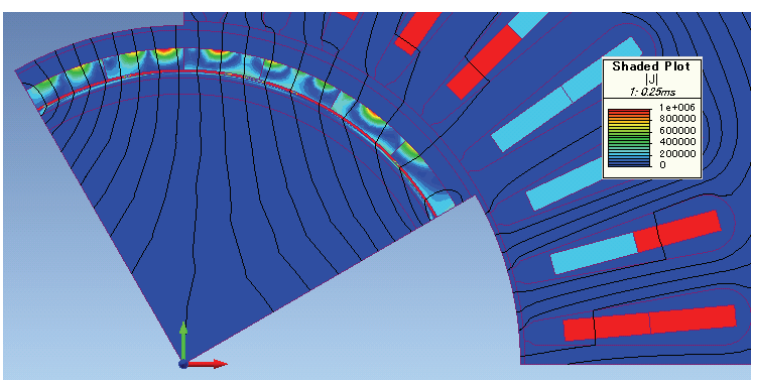

(b) Damper of $0.4 \mathrm{~mm}$ thickness

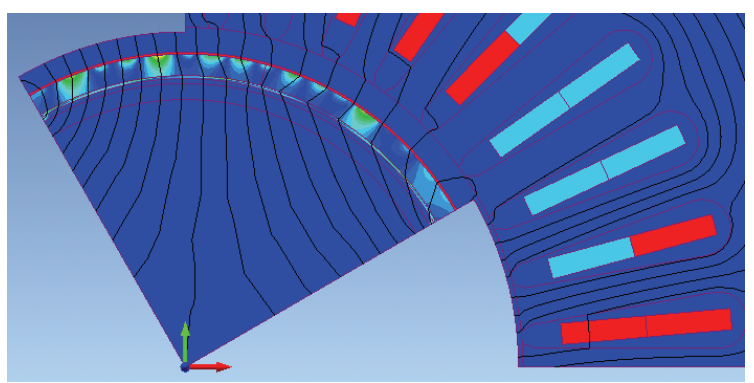

(c) Damper of $0.4 \mathrm{~mm}$ thickness, outside the magnet

Fig. 15. Distributions of eddy current.

waveform is given by 2-level inverter with reactors. This condition is similar to No. 9 or 11 , except the existence or position of the damper. The results are indicated as No. 21 in Table 3 and Fig. 14, and Fig. 15(c). The total loss in the rotor is $105.3 \mathrm{~W}$. Most of the loss is generated in the damper.

The loss could not be reduced than authors expected. The skin depth of the damper is $0.73 \mathrm{~mm}$ at $8 \mathrm{kHz}$ as indicated in Table 1. This means that the spatial harmonic is mostly reduced by thin rotor sleeve if it is installed on the surface of the magnet. Most of spatial flux harmonics, as well as the time harmonics, are blocked on the rotor sleeve and transformed to eddy current loss. This yields the increase of eddy current loss in the damper. In addition to the rotor damper outside the magnet, a similar phenomenon was reported on the magnet pieces with aluminum plating ${ }^{(14)}$.

If the rotor damper installed behind the magnet, spatial flux harmonics reaches to the damper though the magnet pieces. The skin depth of the magnet is $6.3 \mathrm{~mm}$ at $8 \mathrm{kHz}$ as indicated in Table 1, while the thickness of the magnet is $4.0 \mathrm{~mm}$ as in Table 2. Some of spatial harmonics may reach to the surface of the rotor damper. But in addition to the skin effect in the magnet, the strength of the spatial harmonics is more weakened, because the distance from the teeth to the rotor damper is comparable to the teeth pitch. Indeed, the teeth pitch of this motor is about $9.6 \mathrm{~mm}$ and the distance from the teeth to the rotor damper is $9.0 \mathrm{~mm}$. Thus, the rotor damper is hardly 


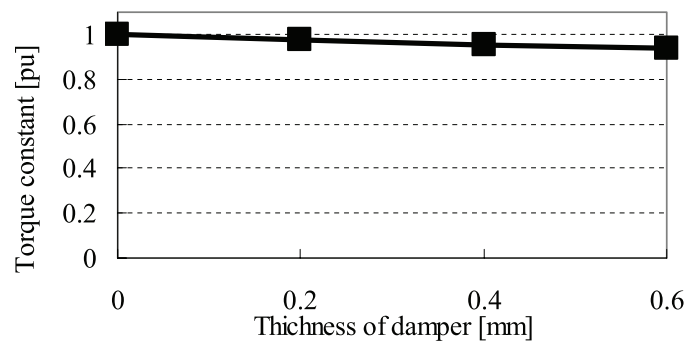

Fig. 16. Reduction of torque constant.

affected by the spatial flux harmonics. The loss in the damper is mainly caused by time harmonics of the PWM currents. It should be noted that the eddy current loss in the magnet can be reduced even if the damper is behind the magnet, because the damper reduces the time harmonics of the total flux generated by the PWM current as indicated in Fig. 4.

If there is not enough space between the rotor and the stator, the diameter of the rotor shaft may be reduced to insert the damper. This yields the reduction of the torque constant of the motor. The reduction of torque constant of the motor is shown in Fig. 16. In the case of $0.4 \mathrm{~mm}$ thickness of the damper, the reduction of torque constant is about $4.5 \%$ which is not a negligible quantity. In the motor used for the experiments of the next section, the actual air gap is narrowed to avoid the reduction of torque constant.

\section{Experimental Results}

4.1 Measuring Method The high speed motor used for the experimental test is shown in Fig. 17. This motor uses magnetic bearing to suit the high speed use. In order to evaluate the effectiveness of the rotor damper, two kinds of rotors are prepared, one is with $0.4 \mathrm{~mm}$ thickness rotor damper and the other is without the damper.

Because the rotor is covered with rotor sleeve and the rotating speed is very high, it is very difficult to measure the rotor temperature directly. Instead of the direct measurement, the physical expansion of the rotor is measured. The temperature of the rotor is calculated by this expansion by using the coefficient of the thermal expansion of the rotor shaft.

Two displacement sensors, which are built in the motor case, are used to measure the apparent extension of the rotor shaft. In addition to these built-in sensors, two displacement gauges are used to measure the extension of motor case.

Let $l_{s}$ and $\Delta l_{s}$ be the span of rotor between built-in sensors and its apparent expansion caused by temperature rise of the motor. Furthermore, let $l_{c}$ and $\Delta l_{c}$ be the span between two displacement gauges measuring the extension of motor case, and its thermal expansion. Then the true expansion of the rotor shaft can be estimated by $\Delta l_{s}+\left(l_{s} / l_{c}\right) \Delta l_{c}$. By using the coefficient of thermal expansion, the average temperature rise $\Delta T$ of the rotor between built-in sensors is calculated by the following.

$$
\Delta T=\frac{1}{\alpha l_{s}}\left(\Delta l_{s}+\frac{l_{s}}{l_{c}} \Delta l_{c}\right) .
$$

Here the constant $\alpha$ is the coefficient of thermal expansion of the rotor shaft material and set to $11.2 \times 10^{-6} 1 / \mathrm{K}$. The measurement construction mentioned above is shown in Fig. 18.

4.2 Results As indicated in Fig. 19, the mechanical

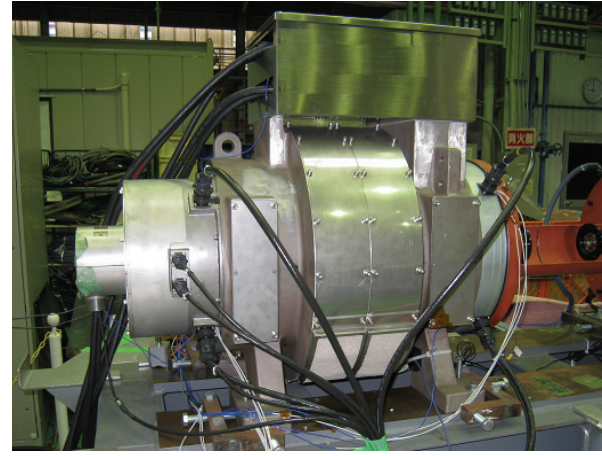

Fig. 17. The motor.

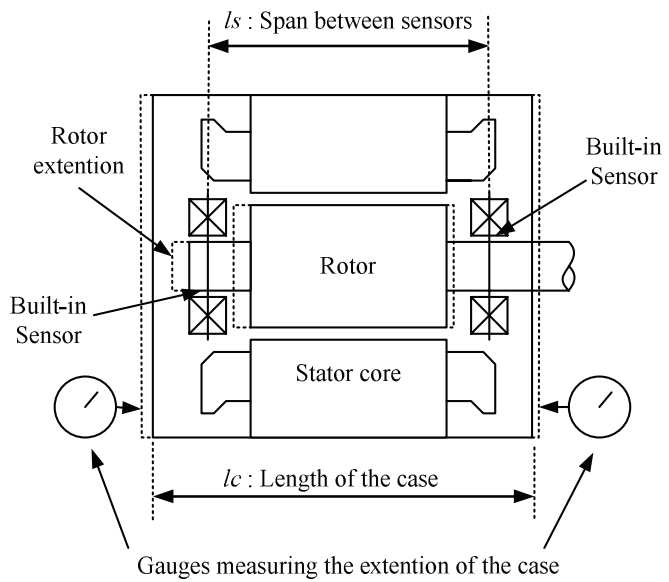

Fig. 18. Measurment of the rotor temperature.

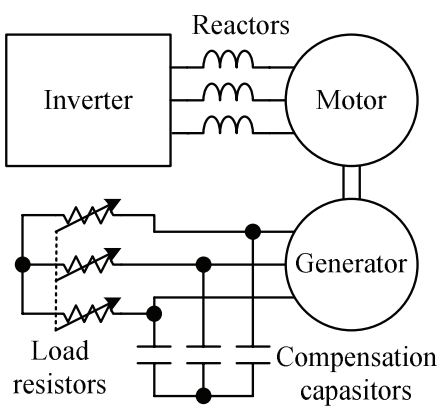

Fig. 19. Back-to-back load test.

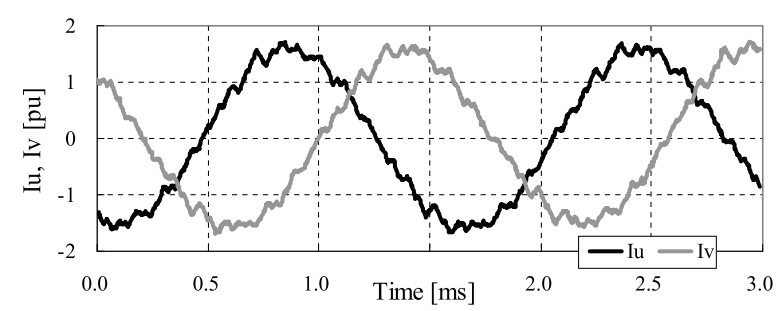

Fig. 20. Actual armature current.

load for the motor is composed by a similar motor which is used as generator and load resistors. Capacitors are also attached to compensate the voltage drop due to the armature inductance of the generator. The motor is driven by 2-level PWM inverter. The filter reactors are inserted between the motor and the inverter. The waveform of the armature current is shown in Fig. 20. The total harmonic distortion is about $6 \%$. 


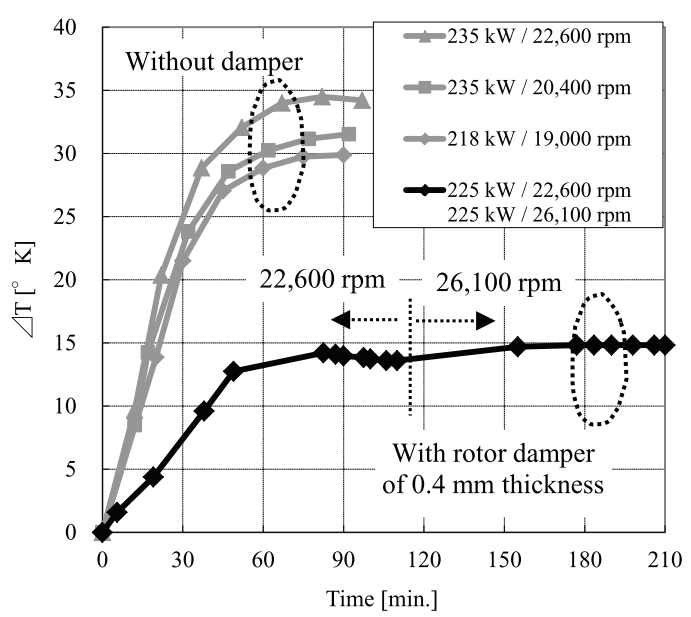

Fig. 21. Temperature rise of the rotor at experiment.

The actual tests using the rotor without damper was done in Dec. 2011, and the actual test using the rotor with damper was done in Aug. 2012 after remaking the rotor. In all the tests, the mechanical load is determined by adjusting the load resistors, while the rotating velocity is determined by the velocity commands fed to the feedback regulator in the inverters. Three test conditions are tried in case of motor without rotor damper, $235 \mathrm{~kW} / 22,600 \mathrm{rpm}, 235 \mathrm{~kW} / 20,400 \mathrm{rpm}$ and $218 \mathrm{~kW} / 19,000 \mathrm{rpm}$. For the motor with rotor damper, test conditions are chosen $225 \mathrm{~kW} / 22,600 \mathrm{rpm}$ and $225 \mathrm{~kW} /$ $26,100 \mathrm{rpm}$. The decrease of the power in case of motor with rotor damper is not caused by the torque reduction due to inserting the rotor damper. It was only caused by the limitation of the test facilities. Unfortunately, more mechanical load was not allowed because of the temperature rise of load resisters in summer conditions.

From the experimental results, the average temperature rises are estimated as shown in Fig. 21. The temperature rise with the rotor damper is about 15 degree $\mathrm{C}$, while the temperature rise without damper is 30 degree $\mathrm{C}$ or more. So the thermal extension of the rotor shaft is reduced by half. Noted that the temperature distribution of the rotor is not uniform. So the maximum temperature rise of the magnet should be estimated higher than the average temperature rise obtained by the proposed method. A simulation example of the temperature distribution is shown in Fig. 22, where the distribution of eddy current loss in the rotor is assumed to be uniform. The ununiformity of the temperature comes from the heat dissipation path. This simulation results shows that the maximum temperature rise of the magnet is approximately twice of the average temperature rise of the rotor. This means that the reduction of the maximum magnet temperature is also much larger than that of average temperature. Experimental results show that the FEM analysis for eddy current loss is adequate and that the damper is effective to reduce the temperature rise of the rotor.

It should be mentioned about the change of electric constants of the motor by inserting the rotor damper. The rotating speed of this motor is controlled by a sensor-less controller. The motor constants are used in the sensor-less controller. As far as our experiments, the change of the control parameters for the sensor-less control is not required. This may be

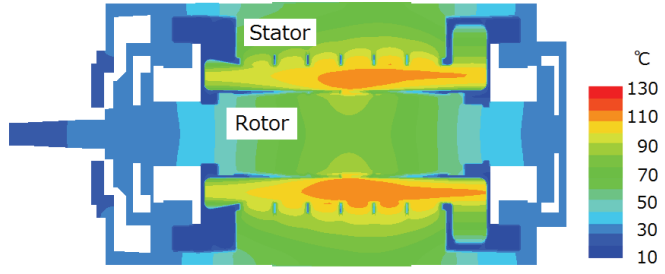

Fig. 22. Simulation example of temperature distribution.

because the parameter change of the motor is restricted only in high frequency range.

\section{Conclusion}

The rotor damper is proposed to reduce the eddy current loss on the rotor. The loss is estimated analytically and numerically. Finite elements analysis shows that the PWM harmonics increase the eddy current loss on the rotor more than five times of sinusoidal drive. It was shown that even the thin cupper plating can reduce the eddy current loss dramatically. By using the rotor damper, eddy current loss on the rotor were decreased less than two times of sinusoidal drive. In addition to the 2-level PWM inverter, eddy current losses with the 3level inverter are estimated by finite elements analysis.

The proposed rotor damper is applied to an actual motor. Experimental results show that the rotor temperature was decreased about fifteen degrees. This implies that the limitation of the Curie temperature of permanent magnet can be mitigated. Furthermore, voluminous and expensive sinusoidal filter can be eliminated by the combination of rotor damper and multi-level inverters.

\section{Acknowledgment}

We would like to express our gratitude to associate professor Tadashi Yamaguchi and Mr. Takashi Kodera of Gifu University for their valuable comments and suggestions.

\section{References}

( 1 ) C. Bailey, D.M. Saban, and P. Guedes-Pinto: "Design of High-Speed DirectConnected Permanent-Magnet Motors and Generators for the Petrochemical Industry", IEEE Trans. Ind. Appl., Vol.45, No.3, pp.1159-1165 (2009)

( 2 ) T. Fukao and A. Chiba: "Super High Speed Drive Technologies", IEEJ Trans. IA, Vol.118, No.2, pp.145-149 (1998) (in Japanese)

( 3 ) H. Kometani and S. Sakabe: "Dynamic Electro-magnetic Analysis of a Permanent Magnet Synchronous Motor with the Supporte Ring Combined with the Inverter Circuit Equations", IEEJ Trans. IA, Vol.115, No.12, pp.14911497 (1995)

( 4 ) H.W. Cho, S.M. Jang, and S.K. Choi: "A Design Approach to Reduce Rotor Losses in High-Speed Permanent Magnet Machine for Turbo-Compressor", IEEE Trans. Mag., Vol.42, No.10, pp.3521-3523 (2006)

( 5 ) K. Miyata, Y. Aoyama, T. Yokoyama, K. Ohashi, M. Kondo, and K. Matsuoka: "3-D Magnetic Field Analysis of Permanent Magnet Motor Considering Magnetizing, Demagnetizing and Eddy Current Loss", IEEJ Trans. $I A$, Vol.123, No.4, pp.401-408 (2003) (in Japanese)

( 6 ) K. Yamazaki and A. Abe: "Loss Analysis of IPM Motors Considering Carrier Harmonics", IEEJ Trans. IA, Vol.127, No.1, pp.87-94 (2007)

( 7 ) K. Yamazaki and A. Abe: "Loss Investigation of Interior Permanent-Magnet Motors Considering Carrier Harmonics and Magnetic Eddy Currents", IEEE Trans. Industry Appl., Vol.45, No.2, pp.659-665 (2009)

( 8 ) K. Miyata, K. Ide, and K. Shinma: "Mode-Filtering Analysis Method of Space and Time Harmonic Wave Components of Magnetic Fields in Rotating Machinery", IEEJ Trans. IA, Vol.128, No.4, pp.516-522 (2008) (in Japanese)

( 9 ) K. Yamazaki, Yu Fukushima, and M. Sato: "Loss Analysis of PermanentMagnet Motors With Concentrated Windings - Variation of Magnet EddyCurrent Loss Due to Stator and Rotor Shapes", IEEE Trans. Industry Appl., 
Vol.45, No.4, pp.1334-1342 (2009)

(10) K. Yamazaki, Y. Kanou, Yu Fukushima, S. Ohji, A. Nezu, T. Ikemi, and R. Mizokami: "Reduction of Magnet Eddy-Current Loss in Interior PermanentMagnet Motors With Concentrated Windings", IEEE Trans. Industry Appl., Vol.46, No.6, pp.2434-2441 (2010)

(11) T. Fukushige: "Influence of the Slot and Pole Number Combination on the Eddy Current Loss of Permanent Magnet Machines", IEEJ Trans. IA, Vol.132, No.10, pp.951-957 (2012) (in Japanese)

(12) M. Nakano, H. Kometani, and M. Kawamura: "A Study on Eddy-Current Losses in Rotors of Surface Permanent Magnet Synchronous Machines", IEEE Trans. Industry Appl., Vol.42, No.2, pp.429-435 (2006)

(13) T. Kosaka, T. Shikayama, and N. Matsui: "An Estimation Approach for PWM Carrier Loss on Rotor in Slotless Permanent Magnet Motors", IEEJ Trans. IA, Vol.125, No.5, pp.511-518 (2005) (in Japanese)

(14) Y. Shindo, K. Hashimoto, and M. Sawada: "Estimation of the Rotor Loss in a Surface Permanent Magnet Motor", Proc. IEEJ IAS Conf., pp.III-185-186 (2009) (in Japanese)

(15) Y. Kawase, T. Yamaguchi, Y. Ono, T. Kodera, Y. Shindo, K. Hashimoto, M. Sawada, and T. Tamiya: "3-D Finite Element Analysis of A Surface Permanent Magnet Motor with Rotor Damper for Loss Reduction”, 2012 Annu. Meeting Record IEEJ (2012) (in Japanese)

(16) P.M. Anderson and A.A. Fouad: "Power System Control and Stability", IEEE Press, pp.107-109 (1993)

(17) P. Kundur: "Power System Stability and Control", McGrawHill, pp.88-93 (1994)

(18) H.A. Wheeler: "Formulas for the Skin Effect", Proc. I.R.E. Sept. 1942, pp.412-415 (1942)

(19) Z. Popovic and B.D. Popovic: "Introductory Electromagnetics", Prentice Hall, pp.383-388 (2000)

Masashi Sawada

(Member) was received the B.E. degree in electrical and electronic engineering and the M.E. degree in electrical engineering of from Kyoto University in 2000 and 2002 respectively. He joined Kawasaki Heavy Industries, Ltd. in 2002. From 2002, he studied and developed electric machines, power conversions and high speed drive systems. In Oct. 2013, he was temporarily transferred to Kawasaki Technology Co. Ltd. and he engages in development of power conversion systems including high speed drive systems

Koji Hashimoto

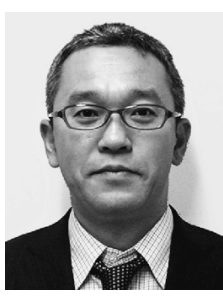

(Member) was born in Fukuoka, Japan, in 1972. He received the B.E. and M.E. degree in electrical engineering from Kyushu University in 1995 and 1997 respectively. He joined Kawasaki Heavy Industries in 1997. From 1997, he had been engaged in development of electric machines and power systems.
Masanori Kuroda (Non-member) was born in Hyogo, Japan, in

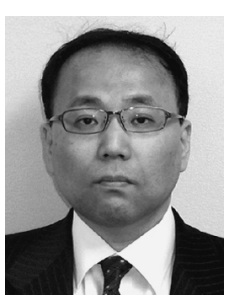
1967. He received the B.E. degree in electrical engineering from Kyoto University in 1991. He joined Kawasaki Heavy Industries in 1991. From 1991, he had been engaged in development of magnets used for particle accelerator, X-ray optical instruments, turbo machines and superconducting electric machines.

Tomoaki Tamiya (Member) was born in Gifu, Japan, in 1984. He

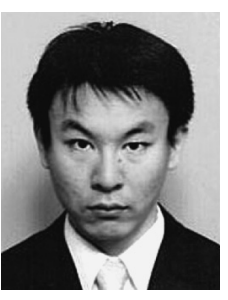
received the B.E. and M.E. degrees in information engineering from Gifu University in 2007 and 2009 respectively. He joined Kawasaki Heavy Industries in 2009. From 2009, he had been engaged in development of electric machines, power conversions and drive systems.

Yuji Shindo (Member) was born in Osaka, Japan, in 1956. He re-

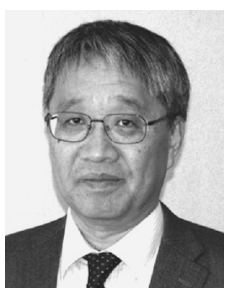
ceived the B.E. degree in electrical engineering from Okayama University in 1979 . He received the M.E. and Dr. Eng. degrees in control engineering from Osaka University in 1981 and 1984, respectively. He joined Kawasaki Heavy Industries in 1984. From 1984, he worked on robotics, servo drives, power conversions, and high speed drive systems. He is a member of IEEE.

Yoshihiro Kawase (Member) was born in Gifu, Japan, on April 24

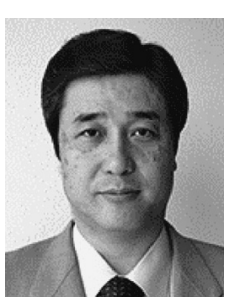
1956. He received a M.S. degree from Okayama University in 1981 and a D.E. degree from Kyoto University in 1986. He was an assistant professor at Okayama University from 1981 to 1985 . He joined Gifu University in 1985, and became an associate professor in 1988. He is presently a professor in the Department of Electrical, Electronic and Computer Engineering at Gifu University from 1997. He had been engaged in development of magnetic field analysis using the 3-D finite element method. IEEE member.
Yuji Kinoshita (Non-member) was born in Osaka, Japan, in 1976. He

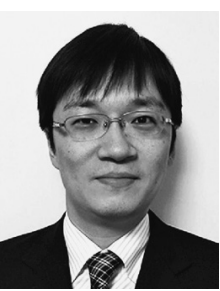
received the B.E. and M.E. degrees in mechanical engineering from Doshisha University in 2000 and 2002 respectively. He joined Kawasaki Heavy Industries in 2002. From 2002, he had been engaged in development of turbo machines and high speed drive systems. 